\title{
A COMPARATIVE EVALUATION OF AIRTRAQ AND MACINTOSH LARYNGOSCOPES FOR DIFFICULT INTUBATION
}

\author{
Prakhar Shukla1, Satyendra Singh Yadav², Vishesh Jain ${ }^{3}$, Girraj Sharma ${ }^{4}$, Hemant Kumar Chourasia 5 , Bhanu Choudhary 6 \\ ${ }_{1}$ Postgraduate Student, Department of Anaesthesiology, G. R. Medical College, Gwalior, Madhya Pradesh. \\ ${ }^{2}$ Assistant Professor, Department of Anaesthesiology, G. R. Medical College, Gwalior, Madhya Pradesh. \\ ${ }^{3}$ Postgraduate Student, Department of Anaesthesiology, G. R. Medical College, Gwalior, Madhya Pradesh. \\ ${ }^{4}$ Postgraduate Student, Department of Anaesthesiology, G. R. Medical College, Gwalior, Madhya Pradesh. \\ ${ }_{5}^{5}$ Associate Professor, Department of Anaesthesiology, G. R. Medical College, Gwalior, Madhya Pradesh. \\ ${ }^{6}$ Professor and HOD, Department of Anaesthesiology, G. R. Medical College, Gwalior, Madhya Pradesh.
}

ABSTRACT
BACKGROUND
Airtraq is an indirect laryngoscope that has demonstrated promise during endotracheal intubation in both normal and difficult
airway scenarios. In this study, we have compared effect of Macintosh and Airtraq laryngoscopes on intubating conditions in
patients at increased risk for difficult tracheal intubation in a randomised controlled trial.

\section{MATERIALS AND METHODS}

Eighty consenting patients presenting for surgery requiring tracheal intubation, who were deemed to possess at least two characteristics indicating an increased risk for difficulty in tracheal intubation were randomly assigned to undergo tracheal intubation using either a Macintosh $(n=40)$ or Airtraq $(n=40)$ laryngoscope. All patients were intubated by anaesthesiologists experienced in the use of both laryngoscopes.

\section{RESULTS}

Two patients were not successfully intubated with the Macintosh laryngoscope, but were intubated successfully with the Airtraq. Airtraq reduced the mean \pm SD duration of 1 st intubation attempt $(52.30 \pm 36.14$ seconds with Macintosh laryngoscope and $34.83 \pm$ 17.45 seconds with Airtraq), mean \pm SD duration of successful intubation attempt $(45.29 \pm 26.58$ seconds with Macintosh laryngoscope and $33.18 \pm 11.06$ seconds with Airtraq), number of intubation attempts required for successful intubation, need for optimisation manoeuvres required during intubation and minor complications during intubation.

\section{CONCLUSION}

Airtraq reduced the difficulty of tracheal intubation compared with the Macintosh laryngoscope in these patients.

\section{KEYWORDS}

Airtraq, Macintosh Laryngoscope.

HOW TO CITE THIS ARTICLE: Shukla P, Yadav SS, Jain V, et al. A comparative evaluation of Airtraq and Macintosh laryngoscopes for difficult intubation. J. Evolution Med. Dent. Sci. 2017;6(72):5098-5102, DOI: 10.14260/jemds/2017/1108

\section{BACKGROUND}

Endotracheal intubation is the placement of a tube into the trachea to maintain a patent airway, in those who are unconscious or unable to maintain their airway for other reasons. Endotracheal intubation provides an artificial conduit between the atmosphere and the patient's trachea for the purpose of alveolar gas exchange and protection of the lungs from aspiration.

Difficult airway is a situation in which a conventionally trained anaesthesiologist experiences difficulty with bag and mask ventilation and tracheal intubation or both. The most dreaded situation during anaesthesia is cannot-ventilatecannot-intubate (CVCI) situation in an apnoeic patient and can lead to life-threatening emergencies like hypoxic brain damage, even death. Recognising of difficult airway before

Financial or Other, Competing Interest: None.

Submission 22-05-2017, Peer Review 24-08-2017,

Acceptance 30-08-2017, Published 07-09-2017.

Corresponding Author:

Dr. Prakhar Shukla,

\#23-Vinay Nagar,

Sector-4, Opposite MPEB,

Gwalior, Madhya Pradesh.

E-mail: prakharshukla2689@gmail.com

DOI: $10.14260 /$ jemds $/ 2017 / 1108$ anaesthesia allows time for optimal preparation, proper selection of equipment and technique and participation of experienced personnel in difficult airway management. Sometime difficult airway is not diagnosed even after induction of anaesthesia, after excluding common causes of difficult airway. The failure to successfully intubate the trachea and secure the airway remains a leading cause of morbidity and mortality in anaesthetic $(1,2,3)$ and emergency settings. $(4,5)$

Airtraq possesses advantages over the Macintosh laryngoscope when used by anaesthesiologists, (6) inexperienced medical personnel(7) and novices.(8) In simulated difficult laryngoscopy scenarios by improving duration of first and successful endotracheal intubation, success rate of endotracheal intubation and reducing number of attempts. Further support for the utility of the Airtraq in clinical settings is likely to be associated with difficult airways comes from reports of its effectiveness in facilitating tracheal intubation in a patient following traumatic asphyxia.(9) Airtraq has also been demonstrated to be effective in morbidly obese patients presenting for surgery.(10) Endotracheal intubation using Airtraq in patients undergoing routine CABG surgery can reduce haemodynamic changes and allow maintaining a stable haemodynamic situation as compared to the Macintosh.(11) 
The purpose of this study is to evaluate the usefulness of Airtraq for use by experienced anaesthesiologist in patients at increased risk for difficult intubation.

In this study, we compared effect of Macintosh and Airtraq laryngoscopes on intubating conditions in patients at increased risk for difficult tracheal intubation by observing intubation time, intubation attempts, associated complications, other manipulations required during intubation, success rate of endotracheal intubation and lowest SpO2 during intubation.

\section{MATERIALS AND METHODS}

A randomised controlled trial was conducted after obtaining approval from the Ethics Committee. The present study was conducted on 80 patients of ASA grade I and II, who underwent various elective surgeries in the Department of Anaesthesiology, JA Group of Hospitals and GR Medical College, Gwalior (MP) after obtaining well informed and written consent from the patients in a randomised controlled trial. Assuming alpha error as 5\%, beta error as $20 \%$, effect size of 0.65 and after accounting for dropouts, sample size was calculated as 80 .

\section{Duration of Study}

Study was conducted from February 2015 to August 2016.

Inclusion Criteria were: Patients of ASA Grade I and II; Patients of age $>18$ years of either Sex; Possession of at least two of the following difficult Intubation Criteria-

1. Thyromental distance $<6 \mathrm{~cm}$;

2. Mallampati classification 3 or 4 ;

3. Interincisor distance $<4 \mathrm{~cm}$;

4. Previously documented difficult intubation;

\section{Exclusion Criteria were: History of Relevant Drug} Allergy; Patient's Refusal

80 patients of ASA grade I and II of either sex scheduled for various elective surgeries under general anaesthesia were divided into 2 groups, $(\mathrm{n}=40$ each). Block randomisation was done to allocate enrolled patients into Airtraq or Macintosh group. There were 4 enrolled patients per block, which were allocated as per sequence of the block. Block randomisation was done to ensure equal number of individuals in both the groups. Groups were-

1. Group 'M' $(n=40)$ - Patients intubated with Macintosh laryngoscope.

2. Group 'A' $(\mathrm{n}=40)$ - Patients intubated with Airtraq.

All anaesthesiologists performing tracheal intubations were skilled for both techniques.

All patients were uniformly premedicated with inj. Glycopyrrolate $0.2 \mathrm{mg}$ IM 30 mins before induction of anaesthesia. Upon arrival of the patient in the operation room, intravenous access with 18G cannula was established and $500 \mathrm{~mL}$ of crystalloid infusion was started. All the baseline vital parameters [ECG for (heart rate) HR; noninvasive blood pressure monitoring (NIBP) for systolic blood pressure (SBP), diastolic blood pressure (DBP) and mean blood pressure (MBP)] were monitored using Mindray monitor with serial number CM-23123730. Oxygen saturation (Sp02) was monitored by using pulse oximeter.
All the drugs were administered by an anaesthesiologist, who was not involved in the study. Patients were premedicated with Inj. Pentazocine $30 \mathrm{mg}$ followed by preoxygenation with $100 \%$ oxygen for 3 minutes. Induction of general anaesthesia was done with IV Inj. Thiopentone Sodium $5 \mathrm{mg} / \mathrm{kg}$ BW. Endotracheal intubation was facilitated with IV Inj. Succinylcholine $2 \mathrm{mg} / \mathrm{kg}$ BW. Endotracheal intubation was done using either Macintosh laryngoscope or Airtraq according to the allotted group. Regular Airtraq (manufactured by Prodol Meditec Limited) of blue colour was used. It permits insertion of endotracheal tubes of size 7.0 8.5. General anaesthesia was maintained with controlled ventilation by using nitrous oxide and oxygen (66:33), loading and maintenance dosage of Atracurium and intermittent Isoflurane $(0.5 \%-1.5 \%)$ by using Bain's anaesthetic circuit.

The Primary Endpoints Related to Endotracheal Intubation were-

- Duration of the Tracheal Intubation Attempts. The duration of intubation attempt is defined as the time taken from insertion of the blade between the teeth until the tracheal tube is placed through the vocal cords as evidenced by visual confirmation by the intubating anaesthesiologist. If the tracheal tube was not visualised passing through the vocal cords, the intubation attempt was not considered complete until the tracheal tube was connected to the anaesthetic circuit and evidence obtained of the presence of carbon dioxide in the exhaled breath through capnography.

- $\quad$ Rate of Successful Placement of the Tracheal Tube in the Trachea. An unsuccessful intubation attempt is defined as an attempt in which the trachea is not intubated or where tracheal intubation attempts terminate after 120 seconds.

- The Optimisation Manoeuvres used to Aid Tracheal Intubation. Optimisation manoeuvres include BURP (Backward Upward Rightward Pressure) manoeuvre; lip retraction; use of a stylet; use of a bougie for Macintosh laryngoscope and BURP manoeuvre; bougie for Airtraq laryngoscope.

- The Number of Intubation Attempts;

- Lowest Recorded Arterial Oxygen Saturation during or immediately following intubation attempts.

- Occurrence of Minor Complications (visible trauma to lip or oral mucosa or blood on laryngoscope or dental trauma).

As this was a study in patients that were potentially difficult to intubate, a two-stage back-up plan was in place in case of a failed intubation. Firstly, in the event of failure to intubate with the device to which the patient was randomly allocated, intubation attempts with the other device were then permitted. In the event that neither devices resulted in successful tracheal intubation, the standard Difficult Airway Society failed Intubation algorithm(12) was followed.

\section{Statistical Analysis}

The observations were recorded and subjected to statistical analysis using appropriate statistical tests like Student's t-test and Chi-square test. The observations recorded in both the groups were tabulated and statistical analysis was carried out 
by using appropriate statistical software (SPSS-17). The $p$-value $>0.05$ was taken to be statistically insignificant and p-value $<0.05$ taken statistically was insignificant.

\section{RESULTS}

A total of 80 patients were entered into the study. No patient who fulfilled the inclusion criteria refused consent to participate in the study; 40 patients were randomly assigned to undergo tracheal intubation using the Macintosh laryngoscope and 40 to undergo tracheal intubation using the Airtraq laryngoscope. There were no significant differences in demographic parameters between the groups (Table 1). All patients recruited possessed at least two of the criteria for difficult intubation. There were no between-group differences with regard to anaesthetic management.

\begin{tabular}{|c|c|c|c|}
\hline Variables & Group M & Group A & P-value \\
\hline Mean Age & $38.75 \pm$ & $35.90 \pm$ & 0.315 \\
( \pm SD) (years) & 13.19 & 11.97 & \\
\hline Mean Weight & $61.22 \pm$ & $65.17 \pm$ & 0.706 \\
$( \pm$ SD) (kg) & 9.85 & 12.01 & \\
\hline Mean Height & $162.25 \pm$ & $162.65 \pm$ & 0.112 \\
$( \pm$ SD) (cm) & 4.20 & 5.18 & \\
\hline Sex M:F & $16: 24$ & $14: 26$ & - \\
\hline Mean ( \pm SD) Duration & $81.00 \pm$ & $92.50 \pm$ & 0.08 \\
of Surgery & 26.21 & 31.56 & \\
(in minutes) & & & \\
\hline \multicolumn{4}{|l|}{ Table 1. Demographic Variables } \\
\hline
\end{tabular}

All patients randomly assigned to the Airtraq laryngoscope group were intubated with the Airtraq laryngoscope on the first attempt (Table 2). In contrast, tracheal intubation was unsuccessful in 2 patients in the Macintosh group. Both these patients were successfully intubated on the first attempt with the Airtraq. Duration of $1^{\text {st }}$ intubation $(p<0.05)$ and duration of successful intubation ( $p$ $<0.05$ ) were significantly reduced in Airtraq group as compared to Macintosh group (Table 2). Number of intubation attempts was significantly decreased in Airtraq group as compared to Macintosh group. In Macintosh group 32 patients required 1 attempt, 5 patients required 2 attempts and 3 patients required 3 attempts. In Airtraq group, 39 patients were intubated in 1 attempt and only 1 patient required 2 attempts (Table 2). Airtraq significantly (p $<0.05$ ) reduced optimisation manoeuvres required during intubation. In Macintosh group optimisation manoeuvres were required in 22 patients, while only 3 patients required optimisation manoeuvres in Airtraq group (Table 2). Complications during intubation were significantly $(\mathrm{p}<0.05)$ reduced with Airtraq than with Macintosh laryngoscope. No complications were seen in Airtraq group, while complications were seen in 5 patients in Macintosh group (Table 2). Mean ( \pm SD) lowest Sp02 in group M was $97.83 \pm$ $6.01 \%$ and in group A was $99.72 \pm 1.08 \%$. The result was statistically insignificant (Table 2). Four patients had SpO2 below $90 \%$, while intubating with Macintosh laryngoscope no such fall in SpO2 was seen with Airtraq

\begin{tabular}{|c|c|c|}
\hline Parameter Assessed & Macintosh & Airtraq \\
\hline Success Rate; N (\%) & $38(95 \%)$ & $40(100 \%)$ \\
\hline Mean ( \pm SD) duration of 1st & $52.30 \pm$ & $34.83 \pm$ \\
intubation attempt (seconds)* & 36.14 & 17.45 \\
\hline Mean ( \pm SD) duration of successful & $45.29 \pm$ & $33.18 \pm$ \\
\hline
\end{tabular}

\begin{tabular}{|c|c|c|}
\hline intubation attempt (seconds) $^{*}$ & 26.58 & 11.06 \\
\hline $\begin{array}{c}\text { Number of intubation } \\
\text { attempts N (\%)* }\end{array}$ & & \\
\hline 1 & $32(80 \%)$ & $39(97.5 \%)$ \\
\hline 2 & $5(12.5 \%)$ & $1(2.5 \%)$ \\
\hline 3 & $3(7.5 \%) \#$ & - \\
\hline $\begin{array}{c}\text { Optimisation Manoeuvres } \\
\text { Required N (\%)* }\end{array}$ & $18(55 \%)$ & $3(7.5 \%)$ \\
\hline Complications N (\%)* & $5(12.5 \%)$ & $0(0 \%)$ \\
\hline Mean ( \pm SD) of lowest & $97.83 \pm$ & $99.72 \pm$ \\
SPO2 (\%)* & $6.01 \%$ & $1.08 \%$ \\
\hline \multicolumn{2}{|c|}{ Table 2. Intubation Parameters } \\
\hline \multicolumn{2}{|c}{}
\end{tabular}

*Significant $(\mathrm{p}<0.05)$ difference;

\$- 4 patients had SpO2 below 90\%, while intubating with Macintosh laryngoscope no such fall in $\mathrm{SpO} 2$ was seen with Airtraq.

\#- tracheal intubation was unsuccessful in 2 patients in the Macintosh group despite 3 intubation attempts.

\section{DISCUSSION}

Management of the potential difficult airway remains a major clinical challenge. Unfortunately, despite predictive tests such as the Mallampati classification, mouth opening and thyromental distance, no single factor reliably predicts these difficulties. Consequently, many difficult intubations will not be recognised until after induction of anaesthesia.

In our study, Airtraq provided superior intubating conditions in patients at increased risk for difficult tracheal intubation. In comparison with the Macintosh laryngoscope, the Airtraq reduced the duration of tracheal intubation attempts, increased the success rate, decreased number of attempts and requirement of optimisation manoeuvres and resulted in fewer minor complications.

Out of 40 intubations, 38 intubations were successfully performed in Macintosh group (95\%) and all intubations were successful in Airtraq group (100\%). Though the successful intubations were more in Airtraq group, the result was clinically insignificant $(\mathrm{p}>0.05)$. Two intubations that were not possible with Macintosh laryngoscope after 3 intubation attempts were successfully done using Airtraq. This was in accordance with:

Maharaj $\mathrm{CH}$ et al(13) compared Airtraq with Macintosh laryngoscope for endotracheal intubation in 40 patients, at increased risk for difficult tracheal intubation. They found increased success rate of endotracheal intubation with Airtraq than with Macintosh laryngoscope, but the result was insignificant $(\mathrm{p}>0.05)$.

Woollard $\mathrm{M}$ et al(14) compared intubation success rates in 23 third-year paramedic students and 56 experienced prehospital practitioners using the Airtraq or a Macintosh laryngoscope. They found that first time intubation success rate was more with Airtraq than Macintosh laryngoscope for both paramedic students and for experienced laryngoscopists.

\section{Duration of $1^{\text {st }}$ Intubation Attempt}

Mean \pm SD of duration of $1^{\text {st }}$ intubation attempt (in seconds) in Macintosh group and Airtraq group were $52.30 \pm 36.14$ and $34.83 \pm 17.45$ seconds respectively. There was significant reduction $(\mathrm{p}<0.05)$ in duration of $1^{\text {st }}$ intubation attempt 
when Airtraq was used as compared to Macintosh laryngoscope. The results are in accordance with-

Maharaj $\mathrm{CH}$ et al(13) compared Airtraq with Macintosh laryngoscope for endotracheal intubation in 40 patients at increased risk for difficult tracheal intubation. They found significant reduction $(\mathrm{p}<0.05)$ in duration of $1^{\text {st }}$ intubation attempt with Airtraq than with Macintosh laryngoscope.

\section{Duration of Successful Intubation Attempt}

Mean \pm SD of duration of successful intubation attempt (in seconds) in Macintosh group and Airtraq group were $45.29 \pm 26.58$ and $33.18 \pm 11.06$ seconds respectively. There was significant reduction $(p<0.05)$ in duration of successful intubation attempt when Airtraq laryngoscope was used as compared to Macintosh laryngoscope as the results are in accordance with-

Maharaj $\mathrm{CH}$ et al(13) compared Airtraq with Macintosh laryngoscope for endotracheal intubation in 40 patients at increased risk for difficult tracheal intubation. They found significant reduction $(p<0.05)$ in duration of successful intubation attempt with Airtraq laryngoscope than with Macintosh laryngoscope.

$\mathrm{Lu} \mathrm{Y}$ et al(15) conducted a systemic review and metaanalysis to compare Airtraq with Macintosh laryngoscopes. They found that Airtraq reduces intubation time significantly as compared to Macintosh laryngoscope.

\section{Intubation Attempts}

Less number of intubation attempts was required in Airtraq group as compared to Macintosh group. With Macintosh laryngoscope 32 intubations $(80 \%)$ were done in single attempt, 5 intubations $(12.5 \%)$ required 2 attempts and 3 intubations $(7.5 \%)$ required 3 attempts; 39 intubations with Airtraq laryngoscope were done in single attempt and 2 attempts were required only in one patient. This reduction of number of attempts for intubation with Airtraq laryngoscope was significant $(p<0.05)$ and in accordance with-

Maharaj $\mathrm{CH}$ et al(13) compared Airtraq with Macintosh laryngoscope for endotracheal intubation in 40 patients, at increased risk for difficult tracheal intubation. They found significant reduction $(p<0.05)$ in number of intubation attempts with Airtraq laryngoscope than with Macintosh laryngoscope.

\section{Intubations Requiring Optimisation Manoeuvres}

$55 \%$ of intubations done in Macintosh group required optimisation manoeuvres as compared to $7.5 \%$ in Airtraq group. The result was significant $(p<0.05)$ and in accordance with-

Bhandari G et al(16) compared Airtraq with Macintosh laryngoscope for endotracheal intubation in 80 patients with normal airways. They found significant reduction $(\mathrm{p}<0.05)$ in number of intubations requiring optimisation manoeuvres with Airtraq laryngoscope as compared to Macintosh laryngoscope.

Gavrilovska-Brzanov A et al(11) compared Airtraq and Macintosh laryngoscopes for haemodynamic response to endotracheal intubation in patients who underwent coronary artery bypass grafting surgery (CABG). They found that rise in pulse rate, systolic blood pressure, diastolic blood pressure and mean blood pressure was significantly more $(\mathrm{p}<0.05)$ with Macintosh laryngoscope than with Airtraq laryngoscope after endotracheal intubation.

\section{Complications during Intubation}

Complications like trauma to lip or oral mucosa or blood on laryngoscope or dental trauma are common during laryngoscopy. In present study fewer complications occurred, while intubating with Airtraq laryngoscope than with Macintosh laryngoscope. Complications occurred in 12.5\% cases in group $\mathrm{M}$ and no complications were seen in group $\mathrm{A}$. The result was statistically significant $(p<0.05)$ and in accordance with-

Maharaj $\mathrm{CH}$ et al(13) compared Airtraq with Macintosh laryngoscope for endotracheal intubation in 40 patients at increased risk for difficult tracheal intubation. They found significant reduction $(p<0.05)$ in number of complications during intubation with Airtraq laryngoscope as compared to Macintosh laryngoscope.

\section{Lowest Sp02 during Intubation}

Mean $( \pm \mathrm{SD})$ of lowest SpO2 during intubation in group $\mathrm{M}$ and group A were $97.83 \pm 6.01 \%$ and $99.72 \pm 1.08 \%$ respectively. Four patients had Sp02 below 90\% while intubating with Macintosh laryngoscope, no such fall in $\mathrm{SpO} 2$ was seen with Airtraq. This decrease of mean $( \pm S D)$ of lowest Spo2 during intubation using Airtraq was insignificant $(p>0.05)$ and in accordance with-

Maharaj $\mathrm{CH}$ et al(17) compared Airtraq with Macintosh laryngoscope for endotracheal intubation in patients with cervical spine immobilisation in a randomised controlled trial done on 40 patients. They found insignificant ( $p>0.05$ ) difference in lowest Sp02 during intubation between Airtraq and Macintosh laryngoscopes.

Ndoko SK et al(18) compared intubation with the Airtraq and Macintosh laryngoscopes in morbidly obese patients in a randomised controlled trial done on 106 patients. They found insignificant $(\mathrm{p}>0.05)$ difference in lowest SpO2 during intubation between Airtraq and Macintosh laryngoscopes.

\section{CONCLUSION}

Airtraq improves intubating conditions in patients at increased risk for difficult intubation as compared to Macintosh laryngoscope by significantly reducing duration of $1^{\text {st }}$ and successful intubation attempt; number of intubation attempts; optimisation manoeuvres required during intubation; associated complications.

Endotracheal intubation with Airtraq is associated with increased success rate and less fall in $\mathrm{SpO} 2$ as compared to Macintosh laryngoscope, but results are insignificant.

\section{REFERENCES}

[1] Caplan RA, Posner KL, Ward RJ, et al. Adverse respiratory events in anesthesia: a closed claims analysis. Anesthesiology 1990;72(5):828-33.

[2] Cheney FW. The American society of anesthesiologists closed claims project: what have we learned, how has it affected practice, and how will it affect practice in the future? Anesthesiology 1999;91(2):552-6.

[3] Peterson GN, Domino KB, Caplan RA, et al. Management of the difficult airway: a closed claims analysis. Anesthesiology 2005;103(1):33-9. 
[4] Mort TC. Emergency tracheal intubation: complications associated with repeated laryngoscopic attempts. Anesthesia and Analgesia 2004;99(2):60713.

[5] Mort TC. Esophageal intubation with indirect clinical tests during emergency tracheal intubation: a report on patient morbidity. J Clin Anesth 2005;17(4):25562.

[6] Maharaj CH, Higgins BD, Harte BH, et al. Evaluation of intubation using the airtraq or macintosh laryngoscope by anaesthetists in easy and simulated difficult laryngoscopy--a manikin study. Anaesthesia 2006;61(5):469-77.

[7] Maharaj CH, Chonghaile M, Higgins BD, et al. Tracheal intubation by inexperienced medical residents using the airtraq and macintosh laryngoscopes-a manikin study. Am J Emerg Med 2006;24(7):769-74.

[8] Maharaj $\mathrm{CH}$, Costello JF, Higgins BD, et al. Learning and performance of tracheal intubation by novice personnel: a comparison of the airtraq and macintosh laryngoscope. Anaesthesia 2006;61(7):671-7.

[9] Black JJ. Emergency use of the airtraq laryngoscope in traumatic asphyxia: case report. Emergency Medicine Journal 2007;24(7):509-10.

[10] Dhonneur G, Ndoko SK, Amathieu R, et al. A comparison of two techniques for inserting the airtraq laryngoscope in morbidly obese patients. Anaesthesia 2007;62(8):774-7.

[11] Gavrilovska-Brzanov A, Jarallah MA, Cogliati A, et al. Evaluation of the hemodynamic response to endotracheal intubation comparing the airtraq with macintosh laryngoscopes in cardiac surgical patients. Acta Inform Med 2015;23(5):280-4.
[12] Henderson JJ, Popat MT, Latto IP, et al. Difficult airway society guidelines for management of the unanticipated difficult intubation. Anaesthesia 2004;59(7):675-94.

[13] Maharaj CH, Costello JF, Harte BH, et al. Evaluation of the airtraq and macintosh laryngoscopes in patients at increased risk for difficult tracheal intubation. Anaesthesia 2008;63(2):182-8.

[14] Woolard M, Lighton D, Mannion W, et al. Airtraq vs standard laryngoscopy by student paramedics and experienced prehospital laryngoscopists managing a model of difficult intubation. Anaesthesia 2008;63(1):26-31.

[15] Lu Y, Jiang H, Zhu YS. Airtraq laryngoscope versus conventional macintosh laryngoscope: a systematic review and meta-analysis. Anaesthesia 2011;66(12):1160-7.

[16] Bhandari G, Shahi KS, Asad M, et al. Airtraq versus macintosh laryngoscope: a comparative study in tracheal intubation. Anesth Essays Res 2013;7(2):232-6.

[17] Maharaj CH, Buckley E, Harte BH, et al. Endotracheal intubation in patients with cervical spine immobilization a comparison of macintosh and airtraq laryngoscopes. Anesthesiology 2007;107(1):53-9.

[18] Ndoko SK, Amathieu R, Tual L, et al. Tracheal intubation of morbidly obese patients: a randomized trial comparing performance of macintosh and airtraq laryngoscopes. British Journal of Anaesthesia 2008;100(2):263-8. 